\title{
Corrosion inhibition properties of 4-methyl-2-(methylthio)-3- phenylthiazol-3-ium iodide on the carbon steel in sulfuric acid medium
}

\author{
M. Zebida, ${ }^{1,2}$ O. Benali, ${ }^{3 *}$ U. Maschke $^{2}$ and M. Trainsel ${ }^{4}$ \\ ${ }^{1}$ Département de chimie, Faculté des sciences, Université de Tlemcen, Algérie \\ ${ }^{2}$ Unité Matériaux et Transformations: Ingénierie des systèmes polymères (UMET:ISP), \\ Université Lillel, France \\ ${ }^{3}$ Département de Biologie, Faculté des sciences, Université de Saïda, Algérie \\ ${ }^{4}$ Unité Matériaux et Transformations, École Nationale Supérieure de Chimie de Lillel, \\ Université Lille1, France \\ *E-mail: benaliomar@hotmail.com
}

\begin{abstract}
Weight loss measurement and electrochemical techniques were used as the methods for studying the inhibition effects of 4-methyl-2-(methylthio)-3-phenylthiazol-3-ium iodide (ST1) on carbon steel corrosion in $0.5 \mathrm{M} \mathrm{H}_{2} \mathrm{SO}_{4}$. The results reveal that corrosion rate of carbon steel decreases with addition of ST1 in $0.5 \mathrm{M} \mathrm{H}_{2} \mathrm{SO}_{4}$. The corrosion rate and inhibition efficiency were found to depend on the concentration of the inhibitor. Inhibition efficiencies up to $99 \%$ can be obtained. The polarization data indicated that the inhibitor was of mixed type, with predominant effect on the cathodic partial reaction. Changes in impedance parameters (charge transfer resistance, $R_{\mathrm{t}}$, and double layer capacitance, $C_{\mathrm{dl}}$ ) confirm that corrosion inhibition was due to adsorption on the metal surface following the Langmuir adsorption isotherm. The results obtained from the three different techniques were in good agreement. The influence of the immersion time shows that the inhibiting molecules form a stable and efficient film. XPS analyses clearly show that the adsorption mechanism of ST1 on the carbon steel surface in $0.5 \mathrm{M} \mathrm{H}_{2} \mathrm{SO}_{4}$ solution is mainly physical adsorption.
\end{abstract}

Key words: C38 steel, EIS, polarization, acid corrosion, XPS.

Received: April 25, 2019. Published: August 13, 2019

doi: $\underline{10.17675 / 2305-6894-2019-8-3-11}$

\section{Introduction}

It is known that among of the major problems of the oil and gas industry is the corrosion of pipes lines made by steels because their resistance to corrosion is very low. Therefore, the use of corrosion inhibitors is among the most popular methods of protecting these materials. These inhibitors are used in small quantities and their adsorption on the surface of the metal forms a protective barrier between the corrosive solution and the material [1-3]. Most inhibitors are synthesized organic compounds containing hetero-atoms such as 
nitrogen, sulfur, phosphorus and/or oxygen [4-6]. Thiazole derivatives have a very high inhibitory effect for steel [7-9], as well as for copper and its alloys [10-12], for aluminum alloy [13] and for zinc [14-15].

In the present investigation an attempt has been made to evaluate the inhibiting action of 4-methyl-2-(methylthio)-3-phenylthiazol-3-ium (ST1) on the corrosion of CS in $0.5 \mathrm{M}$ $\mathrm{H}_{2} \mathrm{SO}_{4}$ solution. Chemical and electrochemical methods were used to determine the rate of corrosion and corrosion inhibition efficiencies. The structure of organic additive used as inhibitor is shown in Figure 1.

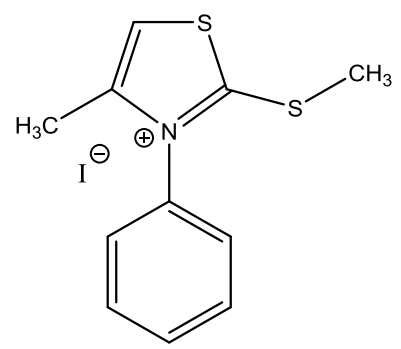

Figure 1. Chemical structure of 4-methyl-2-(methylthio)-3-phenylthiazol-3-ium iodide (ST1).

\section{Experimental}

\subsection{Weight loss studies}

C38 steel sheets having rectangular shape with an exposed area of $2.25 \mathrm{~cm}^{2}$ were used for the corrosion rate measurements. The samples were at first washed with water, grounded with different grades of emery papers, washed with water and rinsed with acetone. The dried and weighed samples were placed in $1 \mathrm{dL}$ of $0.5 \mathrm{M} \mathrm{H}_{2} \mathrm{SO}_{4}$ solutions with and without inhibitor for one hour at $303 \mathrm{~K}$. Multiple experiments were performed in each case and the mean value of the weight loss was noted. Corrosion rate and inhibition efficiency (IE, \%) were calculated.

\subsection{Potentiodynamic polarization studies}

The potentiodynamic polarization studies were carried out with CS strips having an exposed area of one square centimeter. A conventional three electrode cell consisting was used: CS as working electrode, platinum as counter electrode, and a saturated calomel (SCE) as reference electrode. Potentiodynamic polarization studies were carried out using an Autolab Potentiostat-Galvanostat and the data was analyzed using General purpose electrochemical system software. At a constant scan rate of $0.5 \mathrm{mV} / \mathrm{s}$ from open circuit potential (OCP), anodic and cathodic polarization curves were obtained. The inhibition efficiencies were calculated from corrosion currents determined using the Tafel extrapolation method. 


\subsection{Electrochemical impedance studies}

Electrochemical impedance measurements were carried out using an electrochemical system frequency response analyzer (FRA). The electrochemical impedance spectra (EIS) were acquired in the frequency range 10000 to $0.01 \mathrm{~Hz}$ at the OCP by applying $5 \mathrm{mV}$ sine wave $\mathrm{AC}$ voltage. The double layer capacitance (CPE) and the charge transfer resistance $\left(R_{\mathrm{t}}\right)$ were determined from Nyquist plots. The inhibition efficiencies were calculated from $R_{\mathrm{t}}$ values.

\subsection{X-ray photoelectron spectroscopy (XPS)}

X-ray photoelectron spectroscopy (XPS) spectra were recorded by a XPS KRATOS, AXIS Ultra $^{\text {DLD }}$ spectrometer with the monochromatized Al-K $\alpha$ X-ray source $(h v=1486.6 \mathrm{eV})$ and an X-ray beam of around $1 \mathrm{~mm}$. The detailed description and the method of preparation and analysis of the speculators is the same as that described in our previous works $[3,16]$.

\section{Results and discussion}

\subsection{Weight loss measurements}

Table 1 regroups the corrosion parameters obtained from weight loss measurements on the corrosion rate of $\mathrm{CS}$ in $0.5 \mathrm{M} \mathrm{H}_{2} \mathrm{SO}_{4}$. It was observed that a important decrease in dissolution rate occurred over the concentration range from $10^{-6} \mathrm{M}$ to $10^{-3} \mathrm{M}$.

The inhibition efficiency of ST1 for the corrosion of CS was calculated from the Equation 1:

$$
I E_{\mathrm{WL}}=\left(1-\frac{W_{\mathrm{i}}}{W_{0}}\right) \cdot 100,
$$

where $W_{0}$ and $W_{\mathrm{i}}$ are the values of corrosion weight losses of C38 steel in the absence and the presence ST1, respectively.

The inhibition of corrosion of CS by ST1 can be explained in terms of adsorption on the metal surface by the interaction between lone pairs of electrons of heteroatoms such as the sulfur of this compound and the metal surface. The inhibitory effect was explained by the existence of vacant orbitals of low energy in iron atom, as observed in the transition group metals $[3-5,16]$. The inhibition efficiency was estimated to be superior to $60 \%$, even at very low concentration $\left(5 \cdot 10^{-5} \mathrm{M}\right)$, reaching a maximum value $(99 \%)$ at $10^{-3} \mathrm{M}$ of ST1 in the test solution. 
Table 1. Corrosion rate of CS and inhibition efficiency for various concentrations of ST1 for CS corrosion in $0.5 \mathrm{M} \mathrm{H}_{2} \mathrm{SO}_{4}$ at $303 \mathrm{~K}$.

\begin{tabular}{ccc}
\hline $\begin{array}{c}\text { Conc. } \\
(\mathbf{M})\end{array}$ & $\begin{array}{c}\text { Corrosion rate } \\
\left(\mathbf{m g} \cdot \mathbf{c m}^{\mathbf{2}} \cdot \mathbf{h}^{-\mathbf{1}}\right)\end{array}$ & $\begin{array}{c}\boldsymbol{I} \boldsymbol{E}_{\mathrm{WL}} \\
(\boldsymbol{\%})\end{array}$ \\
\hline Blank & 6.65 & - \\
$10^{-6}$ & 6.60 & 07.52 \\
$10^{-5}$ & 4.52 & 32.03 \\
$5 \cdot 10^{-5}$ & 2.66 & 60.00 \\
$10^{-4}$ & 2.32 & 65.11 \\
$5 \cdot 10^{-4}$ & 0.51 & 92.33 \\
$10^{-3}$ & 0.06 & 99.10 \\
\hline
\end{tabular}

\subsection{Polarization studies}

In order to have clear ideas on the kinetics of the cathodic and anodic reactions, potentiodynamic polarization measurements were carried out.

Figure 2 presents the results of the effect of ST1 concentration on the cathodic and anodic polarization curves of CS in $0.5 \mathrm{M} \mathrm{H}_{2} \mathrm{SO}_{4}$, respectively.

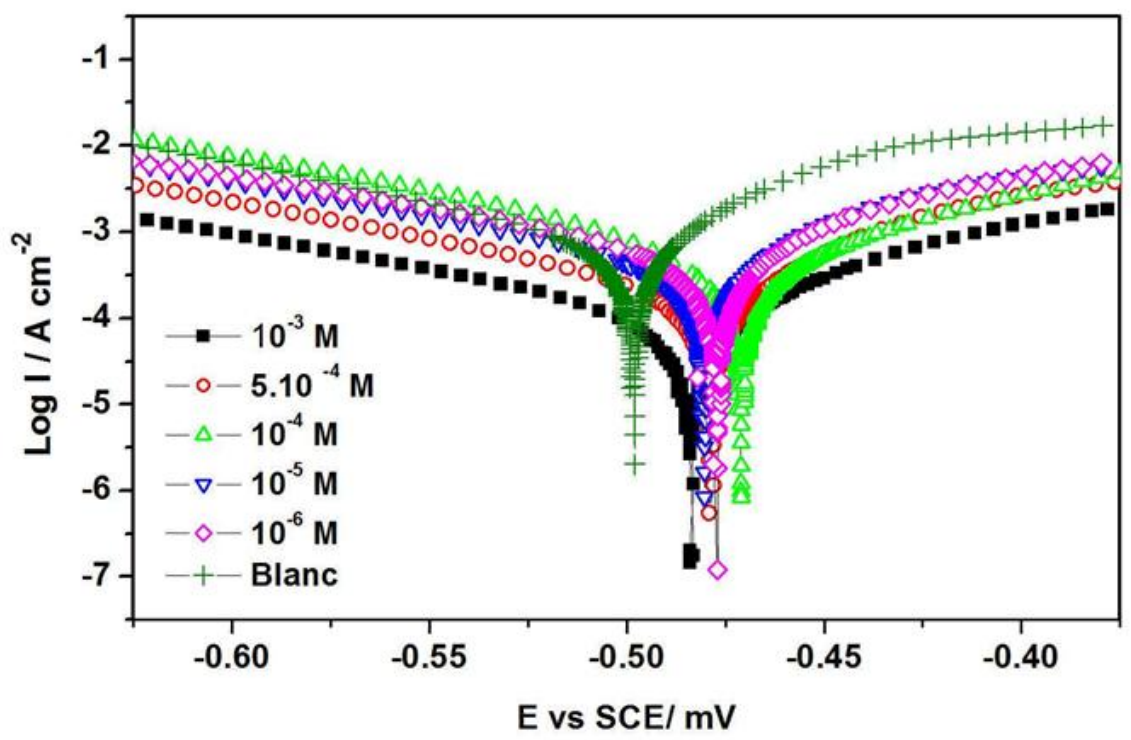

Figure 2. Polarization curves for CS in $0.5 \mathrm{M} \mathrm{H}_{2} \mathrm{SO}_{4}$ containing different concentrations of ST1.

It could be observed that the anodic and cathodic reactions are affected by the addition of the molecules inhibitor (ST1). It should be noted that adsorption and the 
formation of a barrier film on the steel surface by ST1 molecules is the strong point of the latter's inhibitory effect [16].

Electrochemical corrosion kinetic parameters, such as: corrosion potential $\left(E_{\text {corr }}\right)$, corrosion current density $\left(I_{\text {corr }}\right)$, cathodic Tafel slope $\left(b_{c}\right)$ are given in Table 2.

Table 2 also included percentage inhibition efficiency, $I E_{I_{\text {corr }}}(\%)$, which was calculated from the following equation [1]:

$$
I E_{I_{\text {corr }}}(\%)=\left(1-\frac{I_{\text {corr }(\mathrm{i})}}{I_{\text {corr }}}\right) \cdot 100,
$$

where $I_{\text {corr }}$ and $I_{\text {corr(i) }}$ are the corrosion current densities for C38 steel electrode in the uninhibited and inhibited solutions, respectively.

Table 2. Electrochemical parameters and the corresponding corrosion inhibition efficiencies for the corrosion of CS in $0.5 \mathrm{M} \mathrm{H}_{2} \mathrm{SO}_{4}$ containing different concentrations of ST1 at $303 \mathrm{~K}$.

\begin{tabular}{ccccc}
\hline Conc. $(\mathbf{M})$ & $\boldsymbol{E}_{\text {corr }}(\mathbf{m V} \boldsymbol{v s} \mathbf{S C E})$ & $\boldsymbol{b}_{\mathbf{c}}\left(\mathbf{m V} \cdot \mathbf{d e c}^{-\mathbf{1}}\right)$ & $\boldsymbol{I}_{\text {corr }}\left(\mathbf{m A} \cdot \mathbf{c m}^{-\mathbf{2}}\right)$ & $\boldsymbol{I E}_{\boldsymbol{I}_{\text {corr }}}(\boldsymbol{\%})$ \\
\hline Blank & -445 & 199 & 5.22 & - \\
$10^{-6}$ & -446 & 193 & 4.13 & 20.88 \\
$10^{-5}$ & -447 & 222 & 2.37 & 54.60 \\
$5 \cdot 10^{-5}$ & -495 & 190 & 1.65 & 68.39 \\
$10^{-4}$ & -493 & 119 & 1.40 & 73.18 \\
$5 \cdot 10^{-4}$ & -475 & 76 & 0.44 & 91.57 \\
$10^{-3}$ & -491 & 90 & 0.20 & 96.17 \\
\hline
\end{tabular}

The parallel cathodic Tafel curves in Figure 2 for the lower concentrations, suggest that the hydrogen evolution reaction is under the activation regime, that is, the reduction mechanism is not affected by the presence of the inhibitor molecules. But for the higher concentration the cathodic Tafel slopes were found to vary aver a range of 119$76 \mathrm{mV} / \mathrm{dec}$. This result indicates presence of the inhibitor affects the kinetics of hydrogen evolution reaction. Behavior of this type has been observed in our previous work [17] and by other researchers [18].

Table 2 shows that an increase in inhibitor concentration is resulted in decrease of $I_{\text {corr }}$ values and increase of inhibition efficiency. Thus, $I E(\%)$ increases with inhibitor concentration, reaching the value $96 \%$ at the optimal concentration $\left(10^{-3} \mathrm{M}\right)$. 


\subsection{Electrochemical impedance spectroscopy}

Impedance diagrams obtained for frequencies ranging from $10 \mathrm{kHz}$ to $100 \mathrm{mHz}$ at open circuit potential for CS in $0.5 \mathrm{M} \mathrm{H}_{2} \mathrm{SO}_{4}$ in the presence of various concentrations of ST1 are shown in Figure 2. It is clear that theses diagrams are not perfect semicircles. The difference has been attributed to frequency dispersion phenomenon [19].

A semicircular impedance diagram design proves that CS corrosion is controlled by a charge transfer process, so that the presence of ST1 does not alter the dissolution mechanism of the steel in $\mathrm{H}_{2} \mathrm{SO}_{4}$.

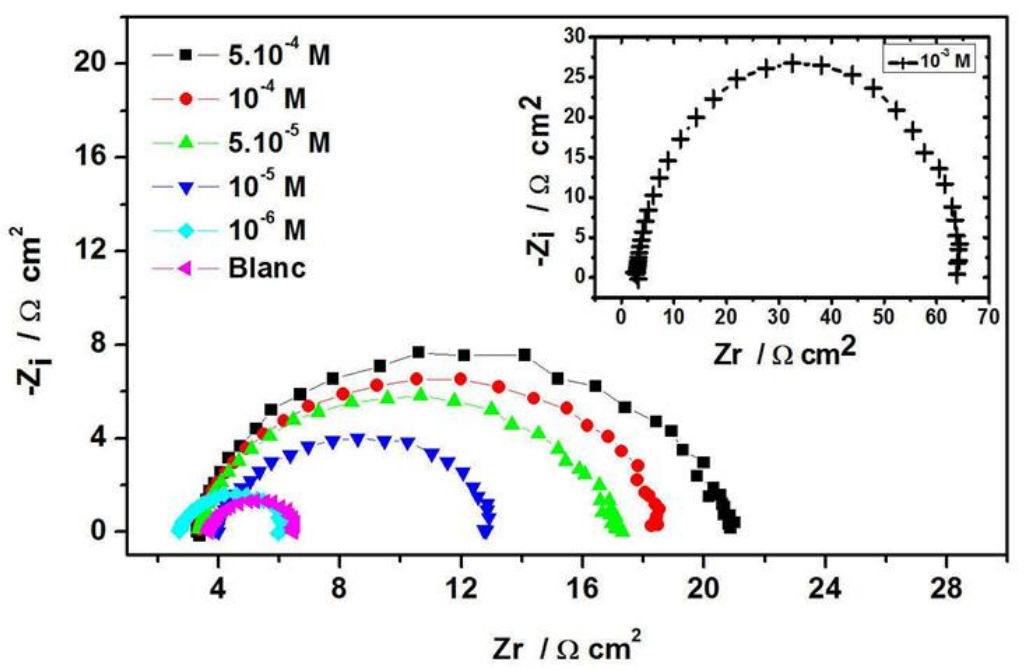

Figure 3. Nyquist plots for $\mathrm{CS}$ in $0.5 \mathrm{M} \mathrm{H}_{2} \mathrm{SO}_{4}$ containing different concentrations of ST1.

The equivalent circuit diagram is suggested as in Figure $4\left(R_{\mathrm{s}}\right.$ : the solution resistance, $R_{\mathrm{t}}$ : the charge transfer resistance, and $C_{\mathrm{dl}}$ : the double layer capacitance).

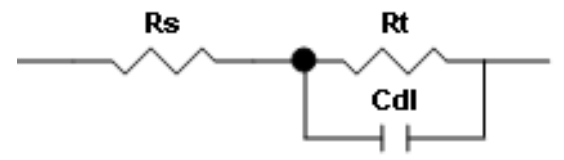

Figure 4. Equivalent circuits used to fit the EIS data.

In this case, the percent inhibition efficiency is calculated by charge transfer resistance, according to the equation:

$$
I E_{R_{\mathrm{t}}}(\%)=\left(1-\frac{R_{\mathrm{t}}}{R_{\mathrm{t}(\mathrm{i})}}\right),
$$

where $R_{\mathrm{t}(\mathrm{i})}$ and $R_{\mathrm{t}}$ are the charge transfer resistance values without and with inhibitor, respectively. 
Table 3 gives the values of the charge transfer resistance $R_{\mathrm{t}}$ double layer capacitance $C_{\mathrm{dl}}$ and inhibition efficiency obtained from the impedance spectra.

Table 3. Impedance parameters recorded for CS electrode in $0.5 \mathrm{M} \mathrm{H}_{2} \mathrm{SO}_{4}$ solution in the absence and presence of ST1 at $303 \mathrm{~K}$.

\begin{tabular}{cccc}
\hline Conc. $(\mathbf{M})$ & $\boldsymbol{R}_{\mathbf{t}}\left(\boldsymbol{\Omega} \cdot \mathbf{c m}^{\mathbf{2}}\right)$ & $\boldsymbol{C}_{\mathbf{d l}}\left(\boldsymbol{\mu F} \cdot \mathbf{c m}^{-\mathbf{2}}\right)$ & $\boldsymbol{E I}_{\boldsymbol{R t}}(\boldsymbol{\%})$ \\
\hline Blank & 2.77 & 397 & - \\
$10^{-6}$ & 3.27 & 329 & 15.29 \\
$10^{-5}$ & 8.53 & 204 & 67.52 \\
$5 \cdot 10^{-5}$ & 12.97 & 203 & 78.64 \\
$10^{-4}$ & 14.31 & 162 & 80.64 \\
$5 \cdot 10^{-4}$ & 16.77 & 155 & 83.48 \\
$10^{-3}$ & 58.39 & 72 & 95.25 \\
\hline
\end{tabular}

As can be seen from this table the increase in resistance in the presence of ST1 (compared to blank solution) is related to the corrosion protection effect of the molecules. The value of $C_{\mathrm{dl}}$ decreases in the presence of this inhibitor, suggesting that the ST1 molecules function by adsorption at the metal solution/interface $[1-4,16]$. The greatest inhibition was observed at concentration of $10^{-3} \mathrm{M}$. The impedance study also confirmed the inhibiting character of ST1 obtained with weight loss measurement and polarization curves.

To predict the influence of the immersion time on the inhibitory efficiency of the molecule under investigation, measurements by electrochemical impedance spectroscopy at different immersion times were performed. The calculated values of $R_{\mathrm{t}}$ and inhibtion effeciency for CS immerssed in the uninhibited and inhibited $\mathrm{H}_{2} \mathrm{SO}_{4} 0.5 \mathrm{M}$ solution by optimal concntration are shown in Table 4.

From this table, we can see that the inhibition efficiency of ST1 increased with immersion time and stabilized after 8 hours. The increase in the inhibition efficiency may be due to the formation of protective adherent film on the metal surface and suggests that the coverage of the metal surface with this film decreases the double layer thickness [1]. The gradual replacement of water molecules by the adsorption of the ST1 molecules to the metal surface has the consequence of the augmentation in the inhibition efficiency $[1,2$, $16]$. 
Table 4. $R_{\mathrm{t}}$ values and inhibition effeciency for CS in $0.5 \mathrm{M} \mathrm{H}_{2} \mathrm{SO}_{4}$ containing the optimal concentration of $\mathbf{S T 1}$ at $303 \mathrm{~K}$.

\begin{tabular}{|c|c|c|c|}
\hline Immersion time & Conc. (M) & $R_{\mathrm{t}}\left(\Omega \cdot \mathrm{cm}^{2}\right)$ & $I E_{R \mathrm{t}}(\%)$ \\
\hline \multirow{2}{*}{$1 \mathrm{~h}$} & $10^{-3} \mathrm{M}$ & 58.39 & 95.25 \\
\hline & Blank & 2.77 & - \\
\hline \multirow{2}{*}{$2 \mathrm{~h}$} & $10^{-3} \mathrm{M}$ & 86.31 & 96.86 \\
\hline & Blank & 2.71 & - \\
\hline \multirow{2}{*}{$4 \mathrm{~h}$} & $10^{-3} \mathrm{M}$ & 90.46 & 97.18 \\
\hline & Blank & 2.55 & - \\
\hline \multirow{2}{*}{$8 \mathrm{~h}$} & $10^{-3} \mathrm{M}$ & 85.68 & 97.16 \\
\hline & Blank & 2.43 & - \\
\hline \multirow{2}{*}{$20 \mathrm{~h}$} & $10^{-3} \mathrm{M}$ & 52.24 & 96.19 \\
\hline & Blank & 1.99 & - \\
\hline \multirow{2}{*}{$24 \mathrm{~h}$} & $10^{-3} \mathrm{M}$ & 50.23 & 96.14 \\
\hline & Blank & 1.94 & - \\
\hline \multirow{2}{*}{48} & $10^{-3} \mathrm{M}$ & 42.58 & 95.80 \\
\hline & Blank & 1.79 & - \\
\hline \multirow{2}{*}{$56 \mathrm{~h}$} & $10^{-3} \mathrm{M}$ & 40.73 & 95.75 \\
\hline & Blank & 1.73 & - \\
\hline \multirow{2}{*}{$72 \mathrm{~h}$} & $10^{-3} \mathrm{M}$ & 36.97 & 95.59 \\
\hline & Blank & 1.63 & - \\
\hline
\end{tabular}

\subsection{Adsorption consideration and XPS Surface analysis}

For the understanding of the mechanism of corrosion inhibition the using of adsorption isotherms are very important. Knowing that there is a direct relationship between the effectiveness of the inhibition and the surface coverage, $\theta$, of the inhibitor, weight loss measurements were used to evaluate surface coverage values, which are given by the Equation 4:

$$
\theta=\frac{I E_{\mathrm{WL}}}{100}
$$

The surface coverage values $(\theta)$ were tested graphically to allow fitting of a suitable adsorption isotherm. 


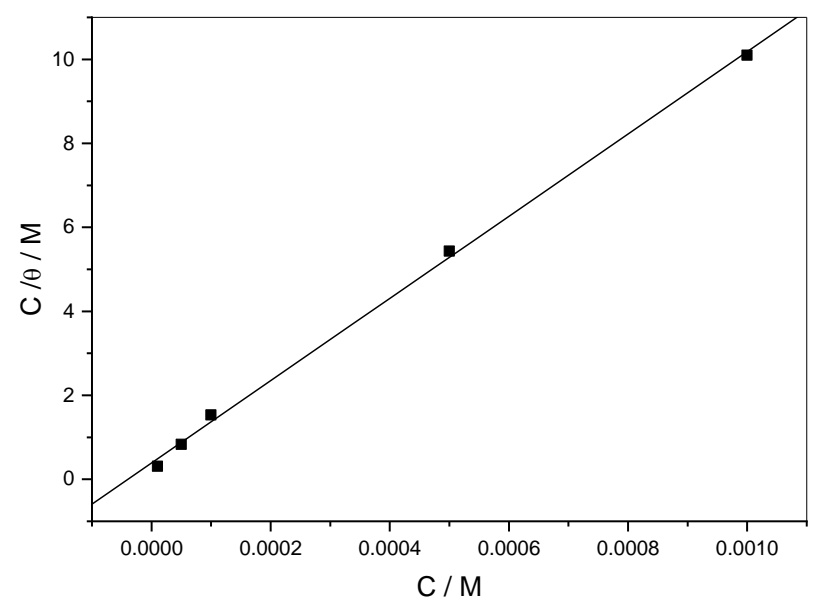

Figure 5. Langmuir adsorption plot of $\mathrm{CS}$ in $0.5 \mathrm{M} \mathrm{H}_{2} \mathrm{SO}_{4}$ solution containing different concentrations of ST1.

The plot of $C / \theta$ versus $C$ (Figure 5) yielded straight lines with slopes close to 1 . This result proves that the adsorption of this compound from $0.5 \mathrm{M} \mathrm{H}_{2} \mathrm{SO}_{4}$ solution on the CS obeys the Langmuir adsorption isotherm.

The following equation presents the linear form of the Langmuir isotherm:

$$
\frac{C}{\theta}=\frac{1}{K_{\mathrm{ads}}}+C,
$$

with

$$
K_{\text {ads }}=\frac{1}{55.5} \exp \left(-\frac{\Delta G_{\text {ads }}}{R T}\right),
$$

where $K_{\text {ads }}$ is the equilibrium constant for the adsorption process, $C$ is the concentration of the inhibitor and $\Delta G_{\text {ads }}$ is free energy of adsorption.

Therefore, obtaining high adsorption equilibrium is a logical justification that the values of inhibition efficiency are high even at low concentrations $67 \%$ of inhibition at $10^{-5} \mathrm{M}$ ). The equilibrium constant obtained in this case (adsorption of ST1 on the surface of the CS) is $2.6 \cdot 10^{4}$. Moreover, the value of $\Delta G_{\mathrm{ads}}$ is equal to $-35.72 \mathrm{~kJ} / \mathrm{mol}$ (large negative value) indicating that the inhibitor molecules are strongly adsorbed on the surface of the CS.

According to the literature, the $\Delta G_{\text {ads }}$ value calculated in this work indicates that the mechanism of adsorption of inhibitory molecules on the C38 steel surface involves two types of interactions: a predominant physisorption and weak chemisorption.

However, and particularly when charged species are adsorbed, it is difficult to distinguish between chemisorption and physisorption only based on these criteria. It should 
be noted that the possibility of Coulombian interactions between adsorbed cations (protonated form of ST1) and specifically adsorbed anions $\left(\mathrm{SO}_{4}^{2-}\right)$ can increase Gibbs' energy even if no chemical bond appears [16].

We can note that a plausible mechanism of corrosion inhibition of CS in $0.5 \mathrm{M} \mathrm{H}_{2} \mathrm{SO}_{4}$ for compound under study may be deduced on the basis of adsorption. In acidic solutions, these inhibitor can exist as cationic specie which may be adsorbed on the cathodic sites of the CS and reduce the evolution of hydrogen. Moreover, the adsorption of ST1 compound on anodic sites through lone pairs of electrons of nitrogen, and sulfuric atoms and through $\pi$-electrons of phenyl group will then reduce the anodic dissolution of CS $[6,16]$.

In order to elucidate the nature of the organic film formed on the CS and confirm this assumption (strong adsorption of ST1), X-ray photoelectron spectroscopy (XPS) analyses are carried out and discussed. For comparison purpose, the XPS spectra were obtained from the pure ST1, and the steel surface which was treated by $10^{-3} \mathrm{M}$ of ST1 after $24 \mathrm{~h}$ of immersion in $0.5 \mathrm{M} \mathrm{H}_{2} \mathrm{SO}_{4}$. The XPS spectra, shown in Figures 6 and 7, were obtained both from pure ST1 (C 1s, N 1s and S 2p) and the ST1 treated carbon steel surface (C 1s, $\mathrm{N} 1 \mathrm{~s}, \mathrm{~S} 2 \mathrm{p}, \mathrm{O} 1 \mathrm{~s}$ and Fe 2p).

The $\mathrm{C}$ 1s spectrum for pure ST1 shows peaks between $285-286.5 \mathrm{eV}$ attributed to the $\mathrm{C}-\mathrm{C}, \mathrm{C}=\mathrm{C}, \mathrm{C}-\mathrm{H}$ bonds for aromatic bonds [20] and $\mathrm{C}=\mathrm{N}, \mathrm{C}-\mathrm{N}, \mathrm{C}-\mathrm{S}$ bonds for thiazole ring [21].

The $\mathrm{N} 1 \mathrm{~s}$ spectrum for pure ST1 can be attributed to the $=\mathrm{N}^{+}\langle$bonds localized at $400-402 \mathrm{eV}$. The S 2p core-level of the pure ST1 is best resolved with at least two spinorbit-split doublets ( $\mathrm{S} 2 \mathrm{p}_{3 / 2}$ and $\mathrm{S} 2 \mathrm{p}_{1 / 2}$ ), with binding energy (BE) for $\mathrm{S} 2 \mathrm{p}_{3 / 2}$ peak lying at about $163-167 \mathrm{eV}$. This former can be assigned to the thiazole ring and $-\mathrm{S}-\mathrm{Me}$.

The I $3 \mathrm{~d}_{5 / 2}$ spectrum for pure ST1 can be attributed to the $\mathrm{I}^{-} / \mathrm{N}^{+}$localized at two binding energies, 618 and $630 \mathrm{eV}$.

After acidic immersion, the C 1s spectrum for ST1 treated C38 steel shows three main peaks (Figure 7a). The first component at $286.4 \mathrm{eV}$ may be assigned to the carbon atoms bonded to: (i) nitrogen in $\mathrm{C}=\mathrm{N}$ and $\mathrm{C}-\mathrm{N}$ bonds in the thiazole ring and (ii) sulfur in $\mathrm{C}-\mathrm{S}$ bond; the second component at a $\mathrm{BE} 285.0 \mathrm{eV}$ is attributed to the the $\mathrm{C}-\mathrm{C}, \mathrm{C}=\mathrm{C}, \mathrm{C}-\mathrm{H}$ aromatic bonds which the largest contribution; the last component at higher binding energy (located at approx. $289 \mathrm{eV}$ ) may be ascribed to the carbon atom of the $\mathrm{C}=\mathrm{N}^{+}$in the tiazole ring [16-22].

Figure $7 \mathrm{~b}$ presents the $\mathrm{O} 1 \mathrm{~s}$ spectrum of $\mathrm{C} 38$ steel surface, after immersion in $0.5 \mathrm{M}$ $\mathrm{H}_{2} \mathrm{SO}_{4}$ solution containing the inhibitor, which may be fitted into three main peaks. The first peak (located at approx. $530.2 \mathrm{eV}$ ) is attributed to $\mathrm{O}^{2-}$, and in principle could be related to oxygen atoms bonded to ferric oxides [23]. The second peak (located at approx. $531.8 \mathrm{eV}$ ) is the most intense component and is ascribable to $\mathrm{OH}^{-}$of hydrous iron oxides [23]. The third peak at $533.5 \mathrm{eV}$ may be associated with the presence of oxygen in the adsorbed water [24]. 


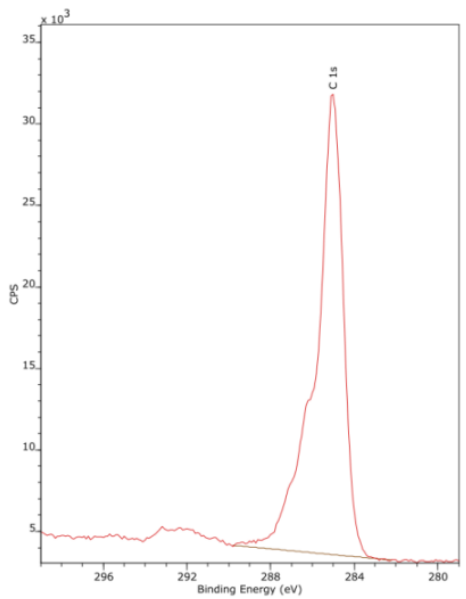

a
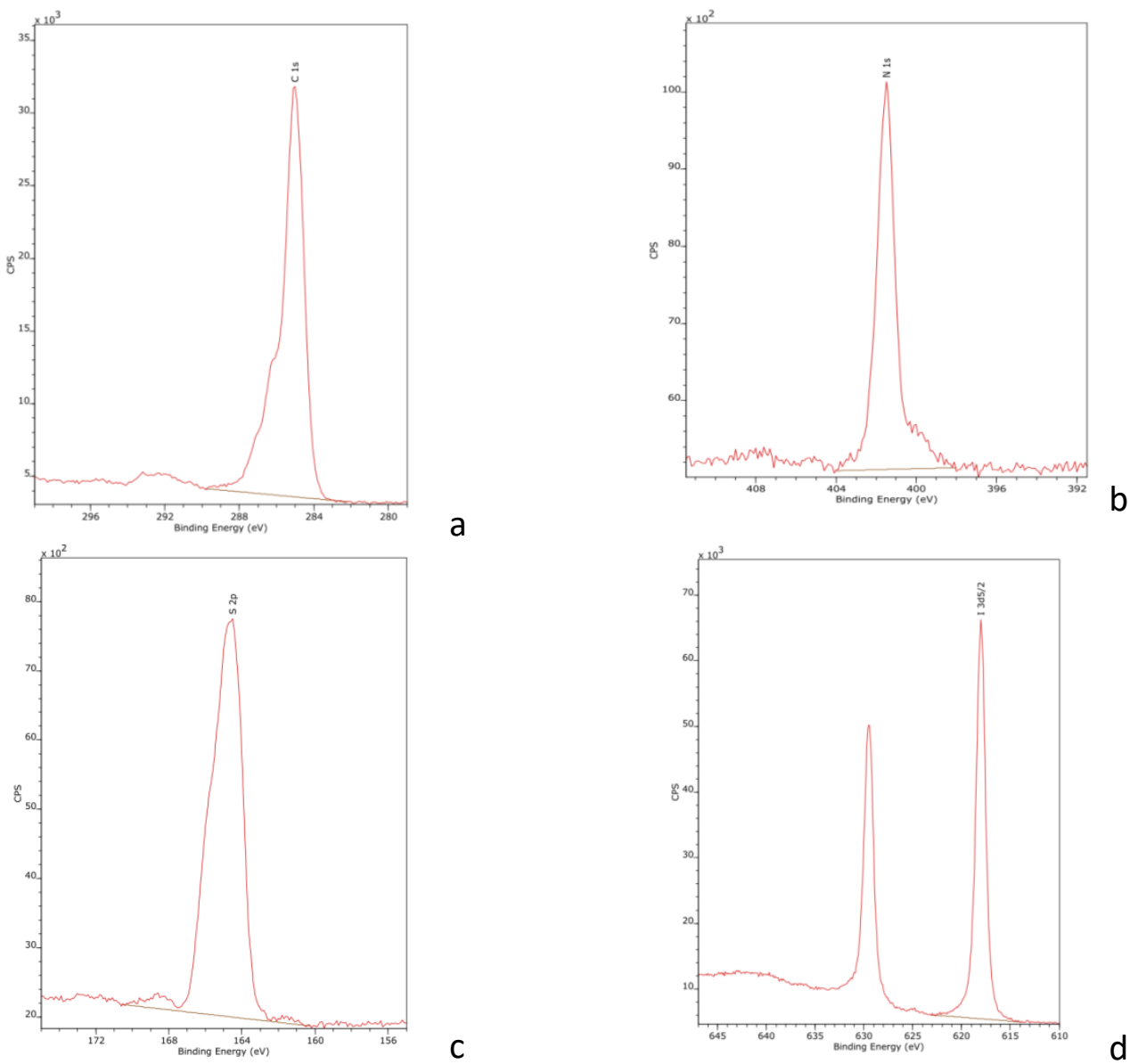

Figure 6. The XPS of a-C 1s, b-N 1s, c-S 2p and d-I 3d for pure ST1.

The $\mathrm{N} 1 \mathrm{~s}$ spectrum of protected CS with ST1 in $0.5 \mathrm{M} \mathrm{H}_{2} \mathrm{SO}_{4}$, given in Figure 7c, shows one main peak, located around 398-402 eV. This later can be ascribed to $=\mathrm{N}^{+}$ in the thiazole ring and to the positively charged nitrogen [25]. The spectrum shows the presence of lower nitrogen content on the steel surface. This indicates that the coordination between the ring via nitrogen atom and the metal surface atoms is very weak.

The S 2p spectrum of the protected CS surface also shows one main peak, located around at $160-171 \mathrm{eV}$ (Figure $7 \mathrm{~d}$ ). The spectrum reflects the presence of lower sulfur content on the CS surface. This peak can be attributed to the $-\mathrm{S}-\mathrm{Me}$ and to $>\mathrm{S}$ structure in the thiazole ring $[26,27]$. Figure 7e presents the $\mathrm{Cl} 2 \mathrm{p}$ XPS spectra of ST1 after adsorption on CS steel in $0.5 \mathrm{M} \mathrm{H}_{2} \mathrm{SO}_{4}$. The spectra observed, shown by the black line, were broad in the binding energy range of 197 to $203 \mathrm{eV}$ and exhibited the two main peaks at 199 and $202 \mathrm{eV}$ approximately. $\mathrm{Cl}(2 \mathrm{p})$ with binding energy $<199 \mathrm{eV}$ is due to inorganic chlorine while values of $>200 \mathrm{eV}$ characterize organic chlorine $(\mathrm{C}-\mathrm{Cl})$ bonds $[28,29]$. 
Finally, the Fe 2p spectrum (Figure 7f) for C38 steel surface covered with ST1 exhibits two doublets, $712 \mathrm{eV}\left(\mathrm{Fe} 2 \mathrm{p}_{3 / 2}\right)$ and $725 \mathrm{eV}\left(\mathrm{Fe} 2 \mathrm{p}_{1 / 2}\right)$, with an associated ghost structure on the high energy side showing the subsequent oxidation of the steel surface [30, 31].
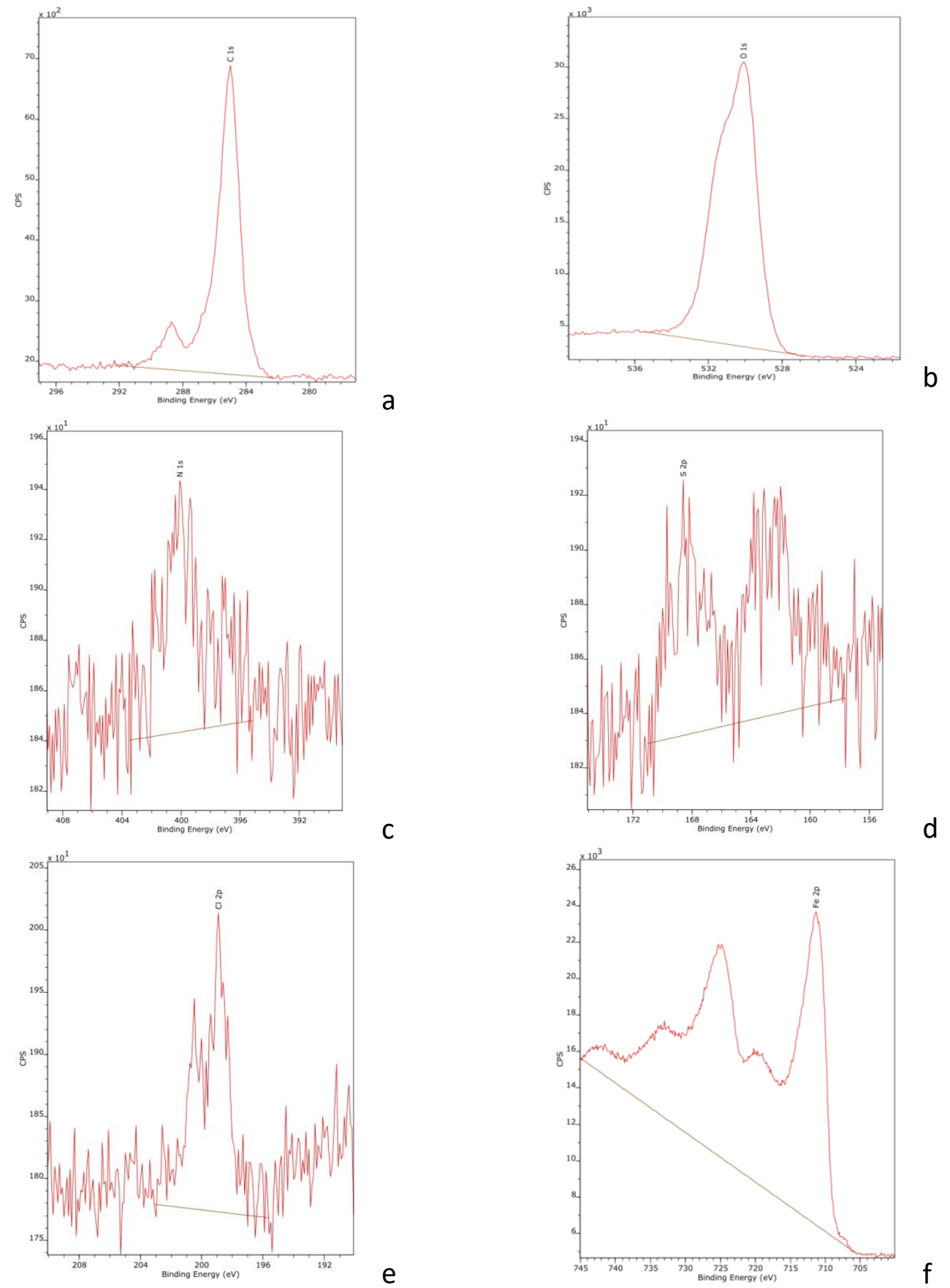

Figure 7. The XPS profiles of a $-\mathrm{C} 1 \mathrm{~s}, \mathrm{~b}-\mathrm{O} 1 \mathrm{~s}, \mathrm{c}-\mathrm{S} 2 \mathrm{p}, \mathrm{d}-\mathrm{N} 1 \mathrm{~s}, \mathrm{e}-\mathrm{Cl} 2 \mathrm{p}$ and $\mathrm{f}-\mathrm{Fe} 2 \mathrm{p}_{3 / 2}$ for ST1 treated C38 steel. 
On the basis of the XPS analyses, the results obtained highlight physical interactions between the ST1 inhibitor and the surface of the CS. In addition, comparison of Fe $2 \mathrm{p}_{3 / 2}$ XPS results for CS after immersion in a $0.5 \mathrm{M} \mathrm{H}_{2} \mathrm{SO}_{4}$ medium containing ST1 with blank shows that the corrosive solution induces a significant decrease in the amount of $\mathrm{Fe}^{0}$ in favor of oxidized species, in particular $\mathrm{Fe}^{3+}$, indicating that the thickness of the oxide layer is increasing $\left(\mathrm{Fe}_{2} \mathrm{O}_{3}\right.$ and $\left.\mathrm{FeOOH}\right)[16]$.

\section{Conclusion}

The 4-methyl-2-(methylthio)-3-phenylthiazol-3-ium iodide (ST1) was used to inhibit the corrosion of CS, and the inhibition efficiency was found to be maximum at $10^{-3} \mathrm{M}$ $(E I=99.1 \%)$. The maximum surface coverage was found to be maximum at this concentration and the molecules of ST1 have formed a protect film which prevents the penetration of acid into the surface of steel. From the polarization curves results, the ST1 is classed as mixed inhibitor. EIS measurements demonstrated that ST1 exhibited the great stability and efficient inhibition performance during a relatively long time. The adsorption followed Langmuir adsorption isotherm, and ST1 can spontaneously adsorb on C38 steel surfaces in acid solution. X-Ray photoelectron spectroscopy (XPS) results show that the inhibition of CS corrosion in $0.5 \mathrm{M} \mathrm{H}_{2} \mathrm{SO}_{4}$ by ST1 is controlled by a physisorption process and the inhibitive layer is composed of an iron oxide/hydroxide mixture where ST1 molecules are incorporated.

\section{References}

1. H.B. Ouici, O. Benali, Y. Harek, L. Larabi, B. Hammouti and A. Guendouzi, Res. Chem. Intermed., 2013, 39, 2777-2793. doi: 10.1007/s11164-012-0797-1

2. H.B. Ouici, O. Benali, Y. Harek, L. Larabi, B. Hammouti and A. Guendouzi, Res. Chem. Intermed., 2013, 39, 3089-3103. doi: 10.1007/s11164-012-0821-5

3. H.B. Ouici, M. Tourabi, O. Benali, C. Selles, M. Traisnel, C. Jama, F. Bentiss and R. Salghi, J. Mater. Environ. Sci., 2016, 7, 2971-2988.

4. O. Benali, L. Larabi, S. Merah and Y. Harek, J. Mater. Environ. Sci., 2011, 2, 39-48.

5. O. Benali and M. Ouazene, Arabian J. Chem., 2011, 4, 443-448. doi: 10.1016/j.arabjc.2010.07.016

6. L. Larabi, O. Benali and Y. Harek, Mater. Lett., 2007, 61, 3287-3291. doi: 10.1016/j.matlet.2006.11.054

7. A. Döner, R. Solmaz, M. Özcan and G. Kardaş, Corros. Sci., 2011, 53, 2902-2913. doi: $\underline{10.1016 / j . c o r s c i .2011 .05 .027}$

8. K. Khaled and M.A. Amin, Corros. Sci., 2009, 51, 1964-1975. doi: 10.1016/j.corsci.2009.05.023

9. M.A. Quraishi, S. Ahmad and G. Venkatachari, Bull. Electrochem., 2002, 18, 399. 
10. E. Abdullayev, V. Abbasov, A. Tursunbayeva, V. Portnov, H. Ibrahimov, G. Mukhtarova and Y. Lvov, ACS Appl. Mater. Interfaces, 2013, 5, 4464-4471. doi: $\underline{10.1021 / \mathrm{am} 400936 \mathrm{~m}}$

11. M. Finšgar and D. Kek Merl, Corros. Sci., 2014, 83, 164-175. doi: 10.1016/j.corsci.2014.02.016

12. G. Vastag, J. Nakomčić and A. Shaban, Int. J. Electrochem. Sci., 2016, 11, 8229-8244.

13. M.L. Zheludkevich, K.A. Yasakau, S.K. Poznyak and M.G.S. Ferreira, Corros. Sci., 2005, 47, 3368-3383. doi: $10.1016 /$ j.corsci.2005.05.040

14. H. Adil, Al-Nahrain J. Sci., 2015, 18, 60-65. doi: 10.22401/JNUS.18.1.08

15. A.V. Shanbhag, T.V. Venkatesha, R.A. Prabhu and B.M. Praveen, Bull. Mater. Sci., 2011, 43, 571-576.

16. H. Ouici，M. Tourabi，O. Benali, C. Selles, C. Jama, A. Zarrouk and F. Bentiss, J. Electroanal. Chem., 2017, 803, 125-134. doi: 10.1016/j.jelechem.2017.09.018

17. O. Benali, L. Larabi, B. Tabti and Y. Harek, Anti-Corros. Methods Mater., 2005, 52, 280-285. doi: $10.1108 / 00035590510615776$

18. M. Lagrenée, B. Mernari, M. Bouanis, M. Traisnel and F. Bentiss, Corros. Sci., 2002, 44, 573-588. doi: 10.1016/S0010-938X(01)00075-0

19. F. Mansfeld, M.W. Kending and S. Tsai, Corrosion, 1982, 38, 570-485. doi: $\underline{10.5006 / 1.3577363}$

20. M. Tourabi, K. Nohair, M. Traisnel, C. Jama and F. Bentiss, Corros. Sci., 2013, 75, 123-133. doi: 10.1016/j.corsci.2013.05.023

21. F. Bentiss, C. Jama, B. Mernari, H. El Attari, L. El Kadi, M. Lebrini, M. Traisnel and M. Lagrenée, Corros. Sci., 2009, 51, 1628-1635. doi: 10.1016/j.corsci.2009.04.009

22. J.F. Watts and J. Wolstenholme, An Introduction to Surface Analysis by XPS and AES, John Wiley and Sons Inc., UK, 2003.

23. W. Temesghen and P.M.A. Sherwood, Anal. Bioanal. Chem., 2009, 373, 601-608. doi: 10.1007/s00216-002-1362-3

24. K. Babić-Samardžija, C. Lupu, N. Hackerman, A.R. Barron and A. Luttge, Langmuir, 2005, 21, 12187-12196. doi: 10.1021/la0517661

25. F. Moulder, W.F. Stickle, P.E. Sobol and K.D. Bomben, Handbook of X-Ray Photoelectron Spectroscopy, Ed: J. Chastain, Perkin-Elmer Corp, Minnesota, USA, 1992.

26. F. Bentiss, M. Traisnel and L. Gengembre, Appl. Surf. Sci., 2000, 161, 194-202. doi: 10.1016/S0169-4332(00)00287-7

27. E.T. Kang, K.G. Neoh and K.L. Tan, Phys. Rev. B, 1991, 44, 10461-10469. doi: 10.1103/PhysRevB.44.10461

28. E. Binner, J. Facun, L.G. Chen, Y. Ninomiya, C.Z. Li and S. Bhattacharya, Energy Fuels, 2011, 25, 2764-2771. doi: 10.1021/ef200250c

29. B. Yang, Y. Cao, F. Qi, X. Li and Q. Xu, Nanoscale Res. Lett., 2015, 10, 207. doi: $\underline{10.1186 / \mathrm{s} 11671-015-0903-6}$ 
30. F.Z. Bouanis, F. Bentiss, M. Traisnel and C. Jama, Electrochim. Acta, 2009, 54, 23712378. doi: $10.1016 /$ j.electacta.2008.10.068

31. A. Galtayries, R. Warocquier-Clérout, M.-D Nagel and P. Marcus, Surf. Interface Anal., 2006, 38, 186-190. doi: $\underline{10.1002 / \text { sia.2295 }}$

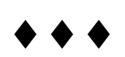

